\title{
Bilateral isolated concurrent superior ophthalmic vein thrombosis in systemic lupus erythematosus
}

This article was published in the following Dove Press journal:

International Medical Case Reports Journal

8 September 2015

Number of times this article has been viewed

\author{
Kumar Sambhav \\ Omar Shakir \\ Kakarla V Chalam \\ Department of Ophthalmology, \\ College of Medicine - Jacksonville, \\ University of Florida, Jacksonville, FL, \\ USA
}

\begin{abstract}
We describe a case of bilateral consecutive superior ophthalmic vein thrombosis as a presenting feature in a patient previously not known to have systemic lupus erythematosus (SLE). A 68-year-old African-American female presented with decreased vision in right eye, mild right orbital tenderness, and frontotemporal headache of 3 days duration. MRI of the orbits confirmed thrombosis of the right superior ophthalmic vein without extension into the cavernous sinus. Sequential MRI at 1 month showed interval improvement of the right superior ophthalmic vein thrombosis and a new thrombosis in the left superior ophthalmic vein. Renal biopsy revealed granular membranous and mesangial deposits of IgG, IgA, IgM, C3, and C1q and confirmed the diagnosis of SLE.
\end{abstract}

Keywords: superior ophthalmic vein thrombosis, systemic lupus erythematosus, MRI in SOVT

\section{Introduction}

Isolated superior ophthalmic vein thrombosis (SOVT) is a rare condition often caused by infections of the midface, Graves' ophthalmopathy, orbital pseudotumor, vascular malformations, and Tolosa-Hunt syndrome. Orbital congestion, proptosis, chemosis, and ophthalmoplegia are seen in patients with superior ophthalmic vein (SOV) occlusion and thrombosis. ${ }^{1}$ MRI and MRV confirm the diagnosis of SOV thrombosis ${ }^{2}$ and exclude the presence of carotid-cavernous sinus fistula, cavernous sinus thrombosis, and sino-orbital infection.

Ocular features are common (34.6\%) in systemic lupus erythematosus (SLE), and lupus retinopathy ${ }^{3}$ is most frequent. Other ocular manifestations include lid involvement, mucocutaneous involvement, secondary Sjögren's syndrome, choroidopathy, and neuro-ophthalmic disorders. SOVT is extremely rare in SLE.

In this report, we describe an isolated bilateral consecutive SOVT as a presenting feature in a patient previously not known to have SLE.

\section{Case report}

A 68-year-old African-American woman presented with nausea, vomiting, and frontotemporal headaches of 3 days duration. Associated symptoms included decreased vision in her right eye and mild right orbital tenderness. Her medical history included hypertension, hyperlipidemia, coronary artery disease, gastroesophageal reflux disease, and goiter status post left lobectomy. Department of Ophthalmology was consulted for evaluation of decreased vision and an abnormal CT scan of the head. 
Best-corrected visual acuity (BCVA) was 20/80 in the right eye and 20/20 in the left eye. Visual fields were full to confrontation. Her intraocular pressure was $30 \mathrm{~mm} \mathrm{Hg}$ in both eyes. Horizontal eye movements were full, except for painful restriction of up and down gaze of the right eye (Figure 1B). Pupils demonstrated 3+ reactivity bilaterally, and there was no relative afferent pupillary defect. Exophthalmometry with a base of $119 \mathrm{~mm}$ was $24 \mathrm{~mm}$ in the right eye and $22 \mathrm{~mm}$ in the left eye. Color vision was normal in both eyes. External examination revealed right superior orbital fullness (Figure 1A) with mild tenderness on palpation. Anterior segment examination was unremarkable. Fundus examination was remarkable for increased cup-to-disc (0.6) ratio in both eyes. There were no choroidal folds or vascular congestion or disc edema.

CT scan of the head showed a hyperdensity within the right SOV. MRI of the orbits confirmed thrombosis of the right SOV without extension into the cavernous sinus (Figure 2A and B). Diagnosis of SLE was confirmed on hematological examination (ANA [antinuclear antibody], anti-Smith antibody and anti-ds DNA were positive) and renal biopsy (Figure 1C) showing histopathological/immunological changes of SLE (granular membranous and mesangial deposits [2+ to $3+]$ of $\operatorname{IgG}, \operatorname{IgA}, \operatorname{IgM}, \mathrm{C} 3$, and C1q).

The patient's orbital fullness and decreased vision improved dramatically after 2 days of steroid (intravenous methylprednisolone $40 \mathrm{mg}$ three times a day) and anticoagulant (intravenous heparin) treatment. Sequential MRI at

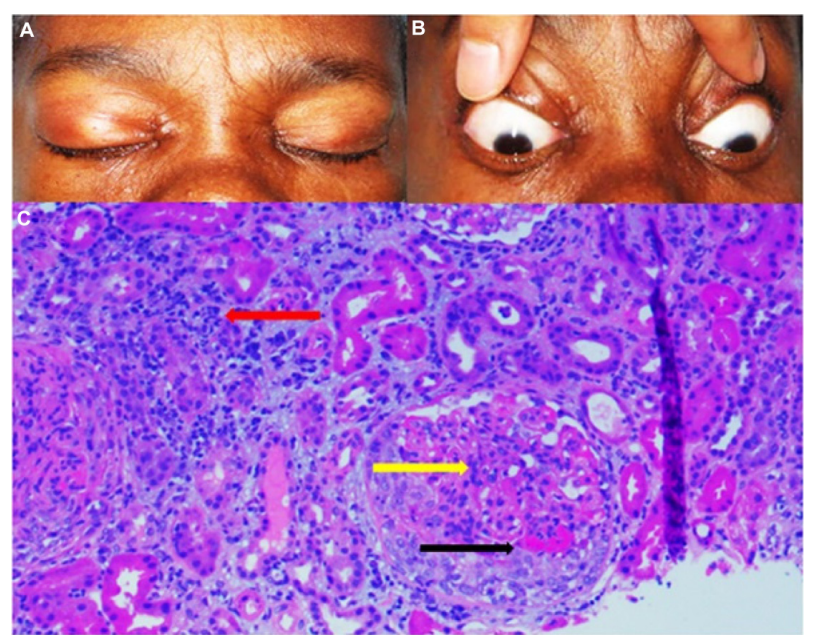

Figure I Clinical picture and $\mathrm{H}$ \& $\mathrm{E}$ staining.

Notes: (A and B) Showing restriction of down gaze in right eye $(\mathbf{A})$ and right orbital fullness (B). (C) Renal biopsy revealed increased endocapillary cellularity (yellow arrow), cellular crescent (black arrow), and chronic interstitial inflammation (red arrow); (H\&E IOX).

Abbreviation: H\&E, hematoxylin and eosin.

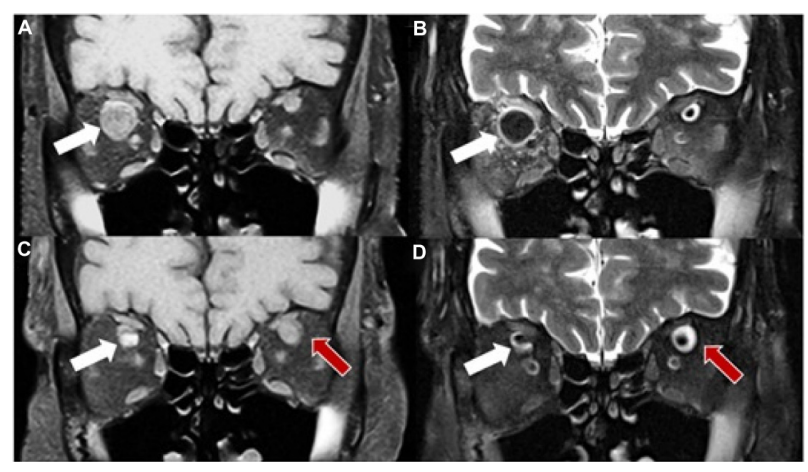

Figure 2 MRI of orbits.

Notes: (A and B) Showing coronal section (TI and T2) at initial presentation. White arrow pointing SOVT in right eye. (C and D) Showing MRI of orbit 4 weeks later; coronal section (TI and T2). White arrow pointing to resolving superior ophthalmic vein thrombosis in right eye. Red arrow pointing to new SOVT in left eye.

Abbreviation: SOVT, superior ophthalmic vein thrombosis; MRI, magnetic resonance imaging.

1 month showed interval improvement of the right SOVT and a new thrombosis in the left SOV (Figure 2C and D).

\section{Discussion}

SOVT (a rare secondary vascular phenomena) is seen in hypercoagulable states (use of oral contraceptive pills, pregnancy, thrombocytosis), infectious diseases (infectious sinusitis, orbital cellulitis), inflammatory diseases (SLE, Behçet syndrome, sarcoidosis, idiopathic orbital inflammation), neoplasms (leukemia, lymphoma, meningioma), trauma, and carotid-cavernous fistula. ${ }^{4}$ SOVT may or may not be associated with cavernous sinus thrombosis. ${ }^{5}$ Congestive signs such as proptosis, ophthalmoplegia, papilledema, chemosis, intraocular hypertension, and retinal venous congestion are usually seen with SOVT. However, thrombosis of orbital veins without extension into the cavernous sinus is rare $^{5}$ and anticoagulation treatment is considered ${ }^{4}$ to obliterate thrombosis.

Isolated SOVT without cavernous sinus involvement is extremely rare. There is a report of a female who developed bilateral SOVT ${ }^{6}$ with associated peripheral retinal hemorrhages, on oral contraceptive pills. Idrees et al, ${ }^{7}$ reported recently a case of bilateral SOV thrombosis secondary to antiphospholipid syndrome in a female with good vision along with associated disc swelling and proptosis. Our patient had good vision on presentation, with minimal orbital congestive signs; BCVA improved to 20/20 after treatment with anticoagulation and steroids.

In conclusion, we report a rare case of bilateral consecutive SOVT as a presenting feature of SLE (confirmed by MRI and histopathology). Early definitive diagnosis and aggressive 
treatment with steroids and anticoagulants usually results in resolution of SOVT and restoration of vision.

\section{Disclosure}

No financial support was received for this submission. The authors report no conflicts of interest in this work.

\section{References}

1. Duke-Elder S. System of Ophthalmology. Vol X. London, UK: Henry Kimpton; 1974:816-819.

2. Lim LH, Scawn RL, Whipple KM, et al. Spontaneous superior ophthalmic vein thrombosis: a rare entity with potentially devastating consequences. Eye. 2014;28:348-351.

3. EL-Shereef RR, Mohamed AS, Hamdy L. Ocular manifestation of systemic lupus erythematosus. Rheumatol Int. 2013;33:1637-1642.
4. Shinder R, Oellers P, Esmaeli B, et al. Superior ophthalmic vein thrombosis in a patient with chronic myeloid leukemia receiving antifibrinolytic and thrombopoietin receptor agonist therapy. J Ocul Pharmacol Ther. 2010;26:293-296.

5. Walker JC, Sandhu A, Pietris G. Septic superior ophthalmic vein thrombosis. Clin Exp Ophthalmol. 2002;30:144-146.

6. Michaelides M, Aclimandos W. Bilateral superior ophthalmic vein thrombosis in a young woman. Acta Ophthalmol Scand. 2003;81(1):88-90.

7. Idrees Z, Dooley I, Jackson A, et al. Simultaneous isolated bilateral superior orbital vein thrombosis as a presenting feature of antiphospholipid syndrome. Orbit. 2014;33(3):214-216.

\section{Publish your work in this journal}

The International Medical Case Reports Journal is an international, peer-reviewed open-access journal publishing original case reports from all medical specialties. Previously unpublished medical posters are also accepted relating to any area of clinical or preclinical science. Submissions should not normally exceed 2,000 words or
4 published pages including figures, diagrams and references. The manuscript management system is completely online and includes a very quick and fair peer-review system, which is all easy to use. Visit http://www.dovepress.com/testimonials.php to read real quotes from published authors.

Submit your manuscript here: http://www.dovepress.com/international-medical-case-reports-journal-journal 